
\title{
3 Research Soure \\ The Control of Crystal Structure and Mechanical Property in Regenerated Cellulose Film by Coagulation Conditions
}

\section{Tessei Kawano}

Kyushu Institute of Technology Graduate School of Life Science and Systems Engineering: Kyushu Kogyo Daigaku Daigakuin Seimeitai Kogaku Kenkyuka

\section{Satoshi likubo}

Kyushu Institute of Technology Graduate School of Life Science and Systems Engineering: Kyushu Kogyo Daigaku Daigakuin Seimeitai Kogaku Kenkyuka

Yoshito Andou ( $\nabla$ yando@life.kyutech.ac.jp)

Kyushu Kogyo Daigaku https://orcid.org/0000-0003-3839-0705

\section{Research Article}

Keywords: regenerated cellulose, alkali-urea solution, coagulation conditions, crystal structure

Posted Date: June 28th, 2021

DOl: https://doi.org/10.21203/rs.3.rs-383197/v1

License: (c) (i) This work is licensed under a Creative Commons Attribution 4.0 International License. Read Full License 


\section{Abstract}

Cellulose films regenerated from aqueous alkali-urea solution possess different properties depending on coagulation conditions. However, the correlation between coagulant species and properties of regenerated cellulose (RC) films has not been clarified yet. In this study, RC films were prepared from cellulose nanofiber (CNF) and microcrystalline cellulose (MCC) under several coagulation conditions. Cellulose dissolved in aqueous $\mathrm{LiOH} / \mathrm{urea}$ solution was regenerated using various solvents at ambient temperature to investigate the effects of their polarity on the properties of RC film. The crystal structure, mechanical properties, and surface morphology of prepared RC films were analyzed using X-ray diffraction (XRD), tensile tester, and atomic probe microscopy (AFM), respectively. It is revealed that the preferential orientation of (110) and (020) crystal planes, which are formed by intra- and inter-hydrogen bonding in cellulose crystal regions, changed depending on coagulant species. Furthermore, we found out that tensile strength, elongation at break, and crystal structure properties of RC film strongly correlate to the dielectric constant of solvents used for coagulation process. This work, therefore, would be able to provide an indicator to control the properties of RC film depending on its application and to develop the detailed research on controlling the crystal structure of cellulose.

\section{Introduction}

The development of a replacement for petroleum-based plastics is becoming more necessary in the face of global warming and plastic pollution. In particular, single-use plastics (SUPs), such as plastic bags, packaging materials, and straws, are substantial sources of plastic pollution (Schnurr et al. 2018). In recent years, many types of bio-based and biodegradable plastic have been developed. For instance, polylactic acid (PLA) is one of the most widely used biodegradable polymers, and PLA-based nanocomposites have attracted interest in a variety of applications (Farah et al. 2016; Moustafa et al. 2017; Niu et al. 2018; Watanabe et al. 2013). Besides, polyhydroxyalkanoates (PHA) has also been expected as an alternative to petroleum-based plastics (Mohammadi et al., 2012; Muneer et al., 2020; Yee et al., 2012). On the other hand, ligno-cellulose have been used as a filler to enhance the property of polymer materials and to reduce the use of petroleum-based plastics (Eksiler et al. 2017, 2019; Kim et al. 2011; Lee et al. 2014; Yasim-Anuar et al. 2020). However, these polymers have certain limitations including low thermal stability, mechanical strength, and biodegradability (Hassanajili et al. 2019; Lee et al. 2020; Sun et al. 2018).

Regenerated cellulose (RC) film, which is composed solely of cellulose, have attracted attention as an environmentally friendly film, especially in food and medicine packaging application due to its biodegradability, gas barrier property, and high mechanical strength (Hyden 1929; Klemm et al. 2005; Ye et al. 2019). Since cellulose does not melt unlike the common thermoplastics due to the strong hydrogen bonding interactions, RC films are generally prepared through dissolution, coagulation, and drying process. Various solvent systems for the dissolution of cellulose have been reported throughout the years, such as carbon disulfide $\left(\mathrm{CS}_{2}\right)$ (Medronho and Lindman 2015), $N$-methylmorpholine- $N$-oxide (NMMO) (Rosenau et al. 2001, 2002; Zhao et al. 2007), and ionic liquids (ILs) (Raut et al. 2015; Swatloski 
et al. 2002; Vitz et al. 2009; Xu et al. 2010; Zavrel et al. 2009). Among these solvent systems, aqueous alkali/urea solution has received considerable attention owing to its simplicity, low toxicity, and rapid dissolution. This solvent system can rapidly dissolve cellulose at low temperature without producing any hazardous byproducts and significant degradation of cellulose (Zhou and Zhang 2000). It has also been reported that the solubility of cellulose in $\mathrm{LiOH} /$ urea aqueous solution is higher than that of $\mathrm{NaOH} / \mathrm{urea}$ solution (Cai and Zhang 2005). In alkali/urea aqueous solution, ${ }^{15} \mathrm{~N}$ and ${ }^{23} \mathrm{Na}$ NMR measurements clarified, adding urea can effectively improve the stability of the alkali-cellulose complex owing to the strong interaction between alkali hydroxides and urea, and low temperature can accelerate the breakdown of intermolecular hydrogen bonding among cellulose, thus prevent the agglomeration of alkali-ureacellulose inclusion complexes (Jiang et al. 2014).

In general, coagulation/regeneration of cellulose from alkali/urea solution is carried out with acidic aqueous solution or polar organic solvents, and it has been discovered that the properties of RC materials, such as crystal structure, mechanical properties, and surface wettability can be varied widely with types of coagulant (Bingbing et al. 2008; Yamane et al. 1996; G. Yang et al. 2007). For instance, regenerated cellulose fibers coagulated with acid aqueous solution, which possesses smaller selfdiffusion coefficients, showed more uniform and finer nanofibril structure, and a superior mechanical strength (Zhu et al. 2018). Besides aqueous solution, the effects of organic coagulants, such as methanol, ethanol, and acetone, on the properties of regenerated cellulose have also been discussed. Isobe et al. have reported the pore size distribution of regenerated cellulose hydrogel is not affected by the type of coagulant, while regenerated cellulose gel coagulated using aqueous solution and organic solvents show different surface morphology and wettability because of the changes in crystal structure (Isobe et al. 2011). Up to now, the effects of coagulation conditions have been widely discussed.

Nevertheless, there is currently no literature that clarifies the correlation between the properties of RC films and the types of coagulant. A central question to reveal this correlation would be how the crystal structure of cellulose changes depending on coagulant species during the regeneration process, and how the changes in crystal structure have an effect on mechanical strength and flexibility of RC films. It is well known that RC has a crystal structure of cellulose $\nabla$ composed of three crystal planes, which are (1-10), (110), and (020) planes (Yamane et al. 2006). In addition, Yamane et al. revealed that (110) and (020) formed by the arrangement of the glucan chains via inter- and intra- hydrogen bonding, while the planar glucan chains were arranged through weak hydrophobic interactions in (1-10) plane. Based on our knowledge, we presumed the polarity of coagulant would have an effect on the interactions among cellulose during the regeneration process, and so the composition of crystal planes, leading to the changes in mechanical properties of RC films. composition of these three crystal planes, and so mechanical strength of RC films. Therefore, the purpose of the present contribution is to investigate the crystal structure, especially the composition of crystal planes and mechanical properties of RC films prepared with various coagulation conditions, and to clarify and visualize the correlation between properties of RC films and types of coagulant. 
In this study, RC films were prepared from cellulose dissolved into $\mathrm{LiOH} /$ urea aqueous solution and coagulated using acid aqueous solution and organic solvents, which have different polarity represented by dielectric constant. The crystal structure of prepared RC films was analyzed using X-ray diffraction (XRD) and we correlated the changes in composition of crystal planes with the polarity of coagulants successfully. In addition, it is clearly revealed that the occupancy of (110) and (020) crystal planes which are formed by strong hydrogen bonding is one of the factors that change the mechanical properties of RC films. This study will expand the detailed research on tuning the crystal structure of cellulose, and provide an indicator to control the properties of RC film depending on its application.

\section{Materials And Methods}

\section{Materials}

The water slurry of cellulose nanofiber (CNF) with the concentration of $5.0 \mathrm{wt} \%$ was provided by Sugino Machine Limited (Toyama, Japan), and stored in a refrigerator before use. Microcrystalline cellulose (MCC) with a particle size of $20 \mu \mathrm{m}$ and lithium hydroxide ( $\mathrm{LiOH}, \geqq 98 \%$ ) were purchased from SigmaAldrich. Urea and all solvents were supplied from Wako Pure Chemical Corporation. All reagents and solvents were laboratory grade and were used as received.

\section{Preparation of regenerated cellulose films}

In this study, regenerated cellulose (RC) films were prepared following a slightly modified procedure of $\mathrm{LiOH} /$ urea aqueous system reported elsewhere (Q. Yang et al. 2011). The solvent mixture comprising $\mathrm{LiOH}$, urea, and $\mathrm{H}_{2} \mathrm{O}$ with a weight ratio of $4.6: 15: 80.4$, containing the desired amount of cellulose, was cooled at $-14{ }^{\circ} \mathrm{C}$ for an hour. Concentration of CNF was fixed at $3 \mathrm{wt} \%$. The cooled mixture was then vigorously stirred for $30 \mathrm{~min}$. Cooling and stirring processes were repeated at least twice in order to make cellulose completely dissolve in $\mathrm{LiOH} / \mathrm{urea}$ aqueous solution. The resulting transparent and viscous solution was degassed by centrifugation at $5^{\circ} \mathrm{C}$ and $8500 \mathrm{rpm}$ for $3 \mathrm{~min}$, spread on a glass plate using a spin coater, and immersed in a coagulation bath at ambient temperature for regeneration. RC films composed of MCC were also prepared from $9 \mathrm{wt} \%$ of $\mathrm{MCC} / \mathrm{LiOH} /$ urea aqueous mixture following the same procedure as CNF.

\section{Characterization}

Chemical structures of pristine CNF, MCC, and RC films were characterized using FT-IR/ATR spectroscopy Nicolet iS5 (Thermo Fisher Scientific K.K., Japan). Transmittance spectra was collected in a wavenumber range of $400-400 \mathrm{~cm}^{-1}$ at a resolution of $4 \mathrm{~cm}^{-1}$. X-ray diffraction (XRD) was performed on a diffractometer MiniFex series (Rigaku Co., Japan) and operated at $40 \mathrm{kV}$ and $15 \mathrm{~mA}$ in reflection mode with Cu Ka radiation $(\lambda=0.154 \mathrm{~nm}$ ), a scanning speed of 10 degree/min along with $2 \theta$ range from 3 to $70^{\circ}$. The refinement of XRD spectra including the breakdown between crystalline and amorphous phases was carried out by using the MAUD Rietveld program (Lutterotti 2010). In this study, crystal information files (.cif) for cellulose $\nabla$ structure (Langan et al. 2001) was used for performing the Rietveld method. The 
preferential formation and orientation of crystal plane formed by intra- and inter- hydrogen bonding among regenerated cellulose crystal region was expressed as a peak-are ratio calculated following equation:

$$
\text { Peak-area ratio }=\frac{\mathrm{A}_{(110)}+\mathrm{A}_{(020)}}{\mathrm{A}_{(1-10)}}
$$

Where $A_{(110)}, A_{(020)}$, and $A_{(1-10)}$ are the peak area of crystalline phases corresponding to (110), (020), and (1-10) planes respectively. Mechanical properties of the RC films were evaluated on a tensilecompressive tester IMC-18E0 (Imoto Machinery Co., Ltd, Japan) at a tensile speed of $5 \mathrm{~mm} / \mathrm{min}$. For each RC film, at least three specimens were tested. Atomic probe microscopy (AFM) AFM5300E (Hitachi HighTech Co., Japan) equipped with silicon cantilever was utilized to characterize the surface morphology and roughness of regenerated cellulose films. The images were recorded in dynamic force mode (DFM).

\section{Results And Discussion}

\section{Preparation process and conditions of regenerated cellulose film}

In this study, regenerated cellulose (RC) films were prepared from microcrystalline cellulose (MCC) and cellulose nanofiber (CNF) using various types of solvent as coagulant to study the effects of the polarity of coagulants on the crystal structure and mechanical properties of RC film. The preparation process and conditions including regeneration bath solutions, coagulation time, and dielectric constant of each solvent were shown in Fig. 1 and Table 1, respectively. Since acidic aqueous medium miscible with cellulose solution easily and destroy the LiOH-urea complex, coagulation by $5 \mathrm{wt} \% \mathrm{H}_{2} \mathrm{SO}_{4}$ aqueous solution containing $5 \mathrm{wt} \% \mathrm{Na}_{2} \mathrm{SO}_{4}$ was carried out for 5 minutes, which is shorter than the coagulation time of other solvents. To prepare the RC films, the aqueous solution composed of cellulose, $\mathrm{LiOH}$, and urea had to be viscous. The CNF solution became viscous enough with lower concentration than the MCC solution. Based on this experience, the concentration of CNF and MCC was adjusted at 3 and $9 \mathrm{wt} \%$ respectively.

The challenge in preparation of RC film was to prevent the shrinkage and bending of film during the drying process. In this study, to overcome this issue, hydrogel-like regenerated cellulose was dried gently under tense state at ambient condition. Figure 2 shows images of RC film prepared from a $3 \mathrm{wt} \% \mathrm{CNF}$ and $9 \mathrm{wt} \% \mathrm{MCC}$ solution in $\mathrm{LiOH} / \mathrm{urea} / \mathrm{H}_{2} \mathrm{O}$ through coagulation with methanol as examples. Highly transparent films with thickness of around $50 \mu \mathrm{m}$ were obtained from both CNF and MCC. 
Table 1

Preparation conditions of regenerated cellulose film and polarity of coagulants

\begin{tabular}{|lll|}
\hline Coagulant & Coagulation time (min) & Dielectric constant \\
\hline $5 \mathrm{wt} \% \mathrm{H}_{2} \mathrm{SO}_{4}$ and $5 \mathrm{wt} \% \mathrm{Na}_{2} \mathrm{SO}_{4}$ & 5 & - \\
\hline $\mathrm{H}_{2} \mathrm{O}$ & 30 & 80.0 \\
\hline Ethylene glycol & 30 & 37.7 \\
\hline Methanol & 30 & 32.6 \\
\hline Ethanol & 30 & 24.3 \\
\hline 1-Butanol & 30 & 17.8 \\
\hline Acetone & 30 & 20.7 \\
\hline$n$-Hexane & 30 & 1.9 \\
\hline
\end{tabular}

\section{Chemical structure of regenerated cellulose films}

FT-IR/ATR spectra of RC films prepared from CNF and MCC through regeneration with methanol, dried mixture composed of cellulose, $\mathrm{LiOH}$, and urea, and the neat $\mathrm{MCC}$ and $\mathrm{CNF}$ are shown in Fig. 3. The broad peak at $3000-3700 \mathrm{~cm}^{-1}$ was assigned to the $\mathrm{O}-\mathrm{H}$ stretching vibrations arising from hydrogen bonding in molecular chains of cellulose. In addition, the spectrum of neat cellulose showed characteristic peaks at around 2900 , and $1000 \mathrm{~cm}^{-1}$ corresponding to the stretching vibration of $\mathrm{C}-\mathrm{H}$ and $\mathrm{C}-\mathrm{O}-\mathrm{C}$, respectively. In the spectrum of dried mixture containing cellulose, $\mathrm{LiOH}$, and urea, three sharp peaks, which are attributed to $\mathrm{N}-\mathrm{H}$ stretching, bending vibration of $\mathrm{N}-\mathrm{H}$, and $\mathrm{C}-\mathrm{N}$ stretching of urea were confirmed at around 3400,1600 , and $1460 \mathrm{~cm}^{-1}$, respectively. All peaks suggesting the presence of urea disappeared and the same spectrum as neat cellulose was obtained after regeneration. These results provide evidence that cellulose was regenerated without derivatization after the removal of urea and LiOH through the coagulation and washing process. A comparison of the native cellulose and RC film, the transmittance peak corresponding to the stretching vibration of $\mathrm{O}-\mathrm{H}$ became more gradual after dissolution and coagulation. This means that the regeneration process has an effect on the intra- and inter- hydrogen bonding in cellulose. RC films coagulated other solvents also showed the same FT-IR spectra as that regenerated with methanol, implying that the functional groups of cellulose did not change depending on the species of coagulants (Fig. S1).

\section{Crystal structure of regenerated cellulose}

The crystal structure of RC films prepared with different types of coagulant was investigated by means of

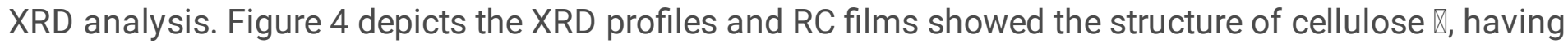
peaks at around $2 \theta=12.5^{\circ}, 20^{\circ}$, and $22.5^{\circ}$ attributing to the (1-10), (110), and (020) crystal plane respectively, while pristine cellulose is classified as cellulose $I_{a}$ or $I_{\beta}$. 
Based on resulting XRD profiles, the relative intensities showed differences for each RC film. The intensity of peak corresponding to $(1-10)$ plane, which is formed by the arrangement of the planar glucan chains via hydrophobic interactions, became stronger than other peaks, as RC films were coagulated with $\mathrm{H}_{2} \mathrm{O}$, ethylene glycol, which possess high polarity and the low polar solvents such as 1-butanol, acetone, and $n$ hexane. In contrast, RC films regenerated using ethanol and methanol as coagulant showed that the intensity of the peaks corresponding to (110) and (020) planes, which are formed by inter- and intrahydrogen bonding, were higher. These results may indicate that the preferred orientation of the crystals was changed in the process of regeneration of cellulose depending on the types of coagulant. The similar behavior was observed for regenerated cellulose gels (Isobe et al. 2011). To demonstrate that preferred orientation is the cause of intensity variation, the RC film sample was cut into small particles with a mill, sieved to obtain a fine powder, and presented to the diffractometer. The XRD profiles of RC film and powdered RC film are shown in Figure S2. The result showed that the diffraction pattern approaches the

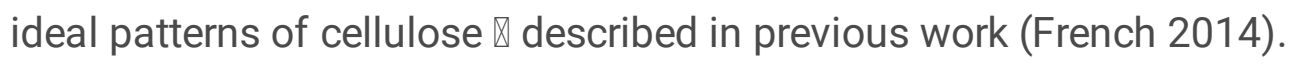

For further investigation, XRD spectra of each RC film was analyzed by using Rietveld method and the peak areas composed of (1-10) and overlapping peaks of (110) and (020) were calculated and the changes in preferred orientation of the crystal planes were evaluated as a peak-area ratio. Figure 5 depicts the result of refinement performed on XRD pattern of RC film prepared from MCC through coagulation using ethanol as an example. The calculated peak-area ratio of the crystal plane formed by intra- and inter-hydrogen bonding in regenerated cellulose coagulated with polar organic solvents, such as ethanol and methanol were much higher than those coagulated with other solvents (Table 2). 
Table 2

Crystal properties of regenerated cellulose film

\begin{tabular}{|c|c|c|c|c|}
\hline \multirow[t]{2}{*}{ Types of cellulose } & \multirow[t]{2}{*}{ Coagulant } & \multicolumn{2}{|l|}{ Peak area } & \multirow{2}{*}{$\begin{array}{l}\text { Peak-area ratio } \\
\left(A_{(110)(020) /(1-10)}\right)\end{array}$} \\
\hline & & $A_{(1-10)}$ & $A_{(110)(020)}$ & \\
\hline \multirow[t]{8}{*}{ CNF } & $5 \mathrm{wt} \% \mathrm{H}_{2} \mathrm{SO}_{4}$ and $5 \mathrm{wt} \% \mathrm{Na}_{2} \mathrm{SO}_{4}$ & 10706.40 & 3887.85 & 0.36 \\
\hline & $\mathrm{H}_{2} \mathrm{O}$ & 6030.11 & 6900.22 & 1.14 \\
\hline & Ethylene glycol & 3049.70 & 9608.20 & 3.15 \\
\hline & Methanol & 2161.39 & 12965.80 & 5.99 \\
\hline & Ethanol & 1825.36 & 8105.36 & 4.44 \\
\hline & 1-Butanol & 13135.90 & 8769.13 & 0.67 \\
\hline & Acetone & 3796.31 & 7145.69 & 1.88 \\
\hline & $n$-Hexane & 6849.58 & 6167.59 & 0.90 \\
\hline \multirow[t]{8}{*}{ MCC } & $5 \mathrm{wt} \% \mathrm{H}_{2} \mathrm{SO}_{4}$ and $5 \mathrm{wt} \% \mathrm{Na}_{2} \mathrm{SO}_{4}$ & 10066.60 & 5441.96 & 0.54 \\
\hline & $\mathrm{H}_{2} \mathrm{O}$ & 13018.40 & 10730.86 & 0.82 \\
\hline & Ethylene glycol & 7022.86 & 8236.69 & 1.17 \\
\hline & Methanol & 3180.77 & 23543.59 & 7.40 \\
\hline & Ethanol & 5064.45 & 22050.30 & 4.35 \\
\hline & 1-Butanol & 12792.60 & 10635.05 & 0.83 \\
\hline & Acetone & 12773.30 & 18001.92 & 1.41 \\
\hline & $n$-Hexane & 14839.20 & 9526.60 & 0.64 \\
\hline
\end{tabular}

\section{Mechanical properties of regenerated cellulose films}

Given the changes in crystal structure of RC films depending on the species of coagulant, the obtained RC films were expected to be different in mechanical properties. That is why a tensile test was conducted to evaluate the mechanical properties of RC film prepared with various coagulants. Figure 6 depicts the stress-strain curves for each RC film prepared from CNF and MCC, and the average of tensile strength, elongation at break, and young's modulus were summarized at Table S1. The mechanical properties of $\mathrm{RC}$ films changed significantly depending on the solvent used as coagulants. In particular, the mechanical properties of MCC-based RC films were strongly affected by the types of coagulant. For instance, the RC film, prepared from $9 \mathrm{wt} \% \mathrm{MCC}$ in $\mathrm{LiOH} / \mathrm{urea} / \mathrm{H}_{2} \mathrm{O}$ through regeneration with ethanol, showed excellent tensile strength of $81.31 \mathrm{MPa}$ and elongation at break of $4.15 \%$. On the other hand, MCC-based RC film coagulated with nonpolar solvents, such as 1-butanol and $n$-hexane was very brittle 
and fragile. As compared with CNF, the elongation at break of RC films prepared from MCC resulted in lower as a whole, due to the difference of aspect ratio between fibrillated cellulose and crystal. However, the tensile strength of MCC-based RC films regenerated with polar organic solvents was as high as that prepared from CNF. These results prove that MCC was packed and formed a fine structure through crystallization during dissolution and coagulation process.

\section{Correlation between polarity of coagulants and properties of regenerated cellulose}

To control the properties of RC film by preparation condition, clarification and visualization of correlation must be crucial. In this study, polarity of coagulants, which is able to be represented in dielectric constant, was adopted as a parameter to investigate the correlation with the mechanical properties and crystal structure of RC films. Figure 7 depicts the peak-area ratio of (110) and (020) lattice planes formed by intra- and inter-hydrogen bonding to (1-10) plane, tensile strength, and elongation at break as a function of dielectric constant of solvents used for coagulation. Both RC films prepared from CNF and MCC show superior mechanical properties, as methanol which has dielectric constant of 32.6 is used for coagulation. Moreover, the peak-area ratio of (110) and (020) crystal planes formed in RC films regenerated with methanol is much higher than RC films coagulated using other solvents. Therefore, there is an apparent correlation between the crystal structure varied in the process of regeneration, mechanical properties of RC films, and dielectric constant of coagulants. These results clearly revealed the correlation that polarity of solvent has a strong effect on the interactions among the molecular chains of cellulose during the regeneration process. In addition, the correlation for RC films prepared from CNF is less apparent compared to MCC. This may be because that fibrillated cellulose molecular intertangle physically during dissolution and coagulation process, due to its high aspect ratio and molecular chain length of CNF.

\section{Surface morphology and roughness of regenerated cellulose films}

It is well known that the property of coagulants affects not only mechanical properties but also surface morphology of regenerated cellulose. In this study, AFM observation was conducted to evaluate the surface morphology and roughness of RC films prepared from $3 \mathrm{wt} \% \mathrm{CNF}$ solution in $\mathrm{LiOH} / \mathrm{urea} / \mathrm{H}_{2} \mathrm{O}$ through coagulation with mixed aqueous solution comprising $5 \mathrm{wt} \% \mathrm{H}_{2} \mathrm{SO}_{4}$ and $5 \mathrm{wt} \% \mathrm{Na}_{2} \mathrm{SO}_{4}$, and methanol. Both of RC films show nanoporous structure, however, there is an obvious difference between the RC films coagulated using aqueous acid solution and organic solvent, which is the former have an agglomerated structure of cellulose fiber (Fig. 8a and C), while the latter shows fibrous structure (Fig. 8b and d). The arithmetical mean height of RC film coagulated using $5 \mathrm{wt} \% \mathrm{H}_{2} \mathrm{SO}_{4}$ and $5 \mathrm{wt} \% \mathrm{Na}_{2} \mathrm{SO}_{4}$ aqueous solution and methanol was calculated based on AFM images, and resulted in 8.05 and $5.77 \mathrm{~nm}$ respectively. This indicates that polar organic solvent penetrates slowly into the cellulose solution to remove $\mathrm{LiOH}$ and urea, and then cellulose molecular chains self-align sufficiently. On the other hand, 
aqueous acid solution diffuses into cellulose solution rapidly, and destroys the LiOH-urea complex immediately. Therefore, cellulose chains cannot form the perfect fibrillated structure and agglomerate each other. These differences of morphology between RC films prepared through coagulation by acid aqueous solution and methanol may support the result that RC film prepared using methanol possess higher tensile strength and elongation than acidic aqueous solution.

\section{Conclusions}

The correlation between the dielectric constant of solvents used for regeneration and the crystal structure as well as mechanical properties of regenerated cellulose films was revealed successfully. It is found that the types of coagulant effect on the occupancy of crystal planes formed by intra- and inter- hydrogen bonding, which is described as (110) and (020) lattice planes. The experimental results demonstrated that RC films prepared from $3 \mathrm{wt} \% \mathrm{CNF}$ and $9 \mathrm{wt} \% \mathrm{MCC}$ solution through regeneration using high-polarity organic solvents, such as methanol and ethanol showed higher occupancy of hydrogen bonding based crystal, tensile strength, and elongation compared to aqueous solution and nonpolar solvents. The findings will be applicable as a parameter to control the properties of regenerated cellulose film depending on its application.

\section{Declarations}

Acknowledgments Authors would like to thank Prof. Teruhisa Ohno from Kyushu Institute of Technology for technical support in sample analysis.

Funding This research received no external funding.

Conflicts of interest The authors declare that they have no conflicts of interest.

Availability of data and material All data and materials support the claims herein and comply with field standards.

Code availability Not applicable.

Author's contributions Conceptualization, Tessei Kawano and Yoshito Andou; methodology, Tessei Kawano; validation, Tessei Kawano; formal analysis, Tessei Kawano; investigation, Tessei Kawano; resources, Yoshito Andou and Satoshi likubo; data curation, Tessei Kawano; writing-original draft preparation, Tessei Kawano; writing-review and editing, Tessei Kawano and Yoshito Andou; visualization, Tessei Kawano; supervision, Yoshito Andou; project administration, Yoshito Andou; funding acquisition, Yoshito Andou. All authors have read and agreed to the published version of the manuscript.

Ethical approval Ethical approval is not applicable for this article.

\section{Compliance with ethical standards}


This article does not contain any studies with human participants or animals performed by any of authors.

\section{References}

1. Bingbing W, Bing L, Jie X, Li CY (2008) Hierarchically ordered polymer nanofibers via electrospinning and controlled polymer crystallization. Macromolecules 41(24):9516-9521. https://doi.org/10.1021/ma801971r

2. Cai J, Zhang $\mathrm{L}$ (2005) Rapid dissolution of cellulose in $\mathrm{LiOH} / \mathrm{urea}$ and $\mathrm{NaOH} /$ urea aqueous solutions. Macromol Biosci 5(6):539-548. https://doi.org/10.1002/mabi.200400222

3. Eksiler K, Andou Y, Ariffin H, Shirai Y (2019) Surface modification for nano-lignocellulose fiber through vapor-phase-assisted surface polymerization. J Polym Sci Part A: Polym Chem 57(24):2575-2580. https://doi.org/10.1002/pola.29532

4. Eksiler K, Andou Y, Yilmaz F, Shirai Y, Ariffin H, Hassan MA (2017) Dynamically controlled fibrillation under combination of ionic liquid with mechanical grinding. J Appl Polym Sci 134(7):1-7. https://doi.org/10.1002/app.44469

5. Farah S, Anderson DG, Langer R (2016) Physical and mechanical properties of PLA, and their functions in widespread applications - A comprehensive review. Adv Drug Deliv Rev 107:367-392. https://doi.org/10.1016/j.addr.2016.06.012

6. French $A D$ (2014) Idealized powder diffraction patterns for cellulose polymorphs. Cellulose 21:8850896. https://doi.org/10.1007/s10570-013-0030-4

7. Hassanajili S, Karami-Pour A, Oryan A, Talaei-Khozani T (2019) Preparation and characterization of $\mathrm{PLA} / \mathrm{PCL} / \mathrm{HA}$ composite scaffolds using indirect 3D printing for bone tissue engineering. Mater Sci Eng C 104:109960. https://doi.org/10.1016/j.msec.2019.109960

8. Hyden WL (1929) Manufacture and properties of regenerated cellulose films. Ind Eng Chem 21(5):405-410. https://doi.org/10.1021/ie50233a003

9. Isobe N, Kim UJ, Kimura S, Wada M, Kuga S (2011) Internal surface polarity of regenerated cellulose gel depends on the species used as coagulant. J Colloid Interface Sci 359(1):194-201. https://doi.org/10.1016/j.jcis.2011.03.038

10. Jiang Z, Fang Y, Xiang J, Ma Y, Lu A, Kang H, Huang Y, Guo H, Liu R, Zhang L (2014) Intermolecular interactions and 3D structure in cellulose- $\mathrm{NaOH}$-urea aqueous system. J Phys Chem $\mathrm{B}$ 118(34):10250-10257. https://doi.org/10.1021/jp501408e

11. Kim D, Andou Y, Shirai Y, Nishida H (2011) Biomass-based composites from poly(lactic acid) and wood flour by vapor-phase assisted surface polymerization. ACS Appl Mater Interfaces 3(2):385391. https://doi.org/10.1021/am1009953

12. Klemm D, Heublein B, Fink HP, Bohn A (2005) Cellulose: Fascinating biopolymer and sustainable raw material. Angew Chem Int Ed 44(22):3358-3393. https://doi.org/10.1002/anie.200460587 
13. Langan P, Nishiyama Y, Chanzy H (2001) X-ray structure of mercerized cellulose $\varangle$ at $1 \AA$ resolution. Biomacromolecules 2:410-416. 10.1021/bm005612q

14. Lee HS, Wakisaka M, Nagasawa N, Nishida H, Andou Y (2014) Development of biocomposites containing erianthus arudinaceus as cellulose resource crops. Kobunshi Ronbunshu 71:31-37. https://doi.org/10.1295/koron.71.31

15. Lee JS, Hwang GH, Kwon YS, Jeong YG (2020) Impacts of cellulose nanofibril and physical aging on the enthalpy relaxation behavior and dynamic mechanical thermal properties of Poly(lactic acid) composite films. Polymer 202:122677. https://doi.org/10.1016/j.polymer.2020.122677

16. Lutterotti $L$ (2010) Total pattern fitting for the combined size-strain-stress-texture determination in thin film diffraction. Nucl Instrum Meth B 268:334-340. https://doi.org/10.1016/j.nimb.2009.09.053

17. Medronho B, Lindman $B$ (2015) Brief overview on cellulose dissolution/regeneration interactions and mechanisms. Adv Colloid Interface Sci 222:502-508. https://doi.org/10.1016/j.cis.2014.05.004

18. Mohammadi M, Hassan MA, Phang LY, Ariffin H, Shirai Y, Ando Y (2012) Recovery and purification of intracellular polyhydroxyalkanoates from recombinant Cupriavidus necator using water and ethanol. Biotechnol Lett 34(2):253-259. https://doi.org/10.1007/s10529-011-0783-5

19. Moustafa H, El Kissi N, Abou-Kandil Al, Abdel-Aziz MS, Dufresne A (2017) PLA/PBAT bionanocomposites with antimicrobial natural rosin for green packaging. ACS Appl Mater Interfaces 9(23):20132-20141. https://doi.org/10.1021/acsami.7b05557

20. Muneer F, Rasul I, Azeem F, Siddique MH, Zubair M, Nadeem H (2020) Microbial polyhydroxyalkanoates (PHAs): Efficient replacement of synthetic polymers. J Polym Environ 28(9):2301-2323. https://doi.org/10.1007/s10924-020-01772-1

21. Niu X, Liu Y, Song Y, Han J, Pan H (2018) Rosin modified cellulose nanofiber as a reinforcing and coantimicrobial agents in polylactic acid /chitosan composite film for food packaging. Carbohydr Polym 183:102-109. https://doi.org/10.1016/j.carbpol.2017.11.079

22. Raut DG, Sundman O, Su W, Virtanen P, Sugano Y, Kordas K, Mikkola JP (2015) A morpholinium ionic liquid for cellulose dissolution. Carbohydr Polym 130:18-25.

https://doi.org/10.1016/j.carbpol.2015.04.032

23. Rosenau T, Potthast A, Adorjan I, Hofinger A, Sixta H, Firgo H, Kosma P (2002) Cellulose solutions in $\mathrm{N}$-methylmorpholine-N-oxide (NMMO) - degradation processes and stabilizers. Cellulose 9(34):283-291. https://doi.org/10.1023/A:1021127423041

24. Rosenau T, Potthast A, Sixta H, Kosma $P$ (2001) The chemistry of side reactions and byproduct formation in the system NMMO/cellulose (Lyocell process). Prog Polym Sci 26(9):1763-1837. https://doi.org/10.1016/S0079-6700(01)00023-5

25. Schnurr REJ, Alboiu V, Chaudhary M, Corbett RA, Quanz ME, Sankar K, Srain HS, Thavarajah V, Xanthos D, Walker TR (2018) Reducing marine pollution from single-use plastics (SUPs): A review. Mar Pollut Bull 137:157-171. https://doi.org/10.1016/j.marpolbul.2018.10.001

26. Sun J, Shen J, Chen S, Cooper MA, Fu H, Wu D, Yang Z (2018) Nanofiller reinforced biodegradable PLA/PHA composites: Current status and future trends. Polymers 10(5):1-22. 
https://doi.org/10.3390/polym10050505

27. Swatloski RP, Spear SK, Holbrey JD, Rogers RD (2002) Dissolution of cellose with ionic liquids. J Am Chem Soc 124(18):4974-4975. https://doi.org/10.1021/ja025790m

28. Vitz J, Erdmenger T, Haensch C, Schubert US (2009) Extended dissolution studies of cellulose in imidazolium based ionic liquids. Green Chem 11(3):417-424. https://doi.org/10.1039/b818061j

29. Watanabe K, Andou Y, Shirai Y, Nishida H (2013) A cross-linked polystyrene supported hindered lithium amide as a deprotonation reagent for a-methylation of lactic acid. Tetrahedron Lett 54(32):4320-4323. https://doi.org/10.1016/j.tetlet.2013.06.019

30. Xu A, Wang J, Wang H (2010) Effects of anionic structure and lithium salts addition on the dissolution of cellulose in 1-butyl-3-methylimidazolium-based ionic liquid solvent systems. Green Chem 12(2):268-275. https://doi.org/10.1039/b916882f

31. Yamane C, Aoyagi T, Ago M, Sato K, Okajima K, Takahashi T (2006) Two different surface properties of regenerated cellulose due to structural anisotropy. Polym J 38(8):819-826. https://doi.org/10.1295/polymj.PJ2005187

32. Yamane C, Mori M, Saito M, Okajima K (1996) Structures and mechanical properties of cellulose filament spun from cellulose/aqueous $\mathrm{NaOH}$ solution system. Polym J 28(12):1039-1047. https://doi.org/10.1295/polymj.28.1039

33. Yang G, Miyamoto $H$, Yamane C, Okajima K (2007) Structure of regenerated cellulose films from cellulose/aqueous $\mathrm{NaOH}$ solution as a function of coagulation conditions. Polym J 39(1):34-40. https://doi.org/10.1295/polymj.PJ2006025

34. Yang Q, Fukuzumi H, Saito T, Isogai A, Zhang L (2011) Transparent cellulose films with high gas barrier properties fabricated from aqueous alkali/urea solutions. Biomacromol 12(7):2766-2771. https://doi.org/10.1021/bm200766v

35. Yasim-Anuar TAT, Ariffin H, Norrrahim MNF, Hassan MA, Andou Y, Tsukegi T, Nishida H (2020) Welldispersed cellulose nanofiber in low density polyethylene nanocomposite by liquid-Assisted extrusion. Polymers 12(4):1-17. https://doi.org/10.3390/POLYM12040927

36. Ye D, Lei X, Li T, Cheng Q, Chang C, Hu L, Zhang L (2019) Ultrahigh tough, super clear, and highly anisotropic nanofiber-structured regenerated cellulose films. ACS Nano 13(4):4843-4853. https://doi.org/10.1021/acsnano.9b02081

37. Yee LN, Mumtaz T, Mohammadi M, Phang LY, Ando Y, Raha AR, Sudesh K, Ariffin H, Hassan MA, Zakaria MR (2012) Polyhydroxyalkanoate synthesis by recombinant escherichia coli JM109 expressing PHA biosynthesis genes from Comamonas sp. EB172. J Microb Biochem Technol 4(5):103-110. https://doi.org/10.4172/1948-5948.1000079

38. Zavrel M, Bross D, Funke M, Büchs J, Spiess AC (2009) High-throughput screening for ionic liquids dissolving (ligno-)cellulose. Bioresour Technol 100(9):2580-2587. https://doi.org/10.1016/j.biortech.2008.11.052

39. Zhao H, Kwak JH, Wang Y, Franz JA, White JM, Holladay JE (2007) Interactions between cellulose and N-methylmorpholine-N-oxide. Carbohydr Polym 67(1):97-103. 
https://doi.org/10.1016/j.carbpol.2006.04.019

40. Zhou J, Zhang $L$ (2000) Solubility of cellulose in $\mathrm{NaOH} /$ Urea aqueous solutions. Polym J 32(10):866-870. https://doi.org/10.1295/polymj.32.866

41. Zhu K, Qiu C, Lu A, Luo L, Guo J, Cong H, Chen F, Liu X, Zhang X, Wang H, Cai J, Fu Q, Zhang L (2018) Mechanically strong multifilament fibers spun from cellulose solution via inducing formation of nanofibers. ACS Sustain Chem Eng 6(4):5314-5321.

https://doi.org/10.1021/acssuschemeng.8b00039

\section{Figures}

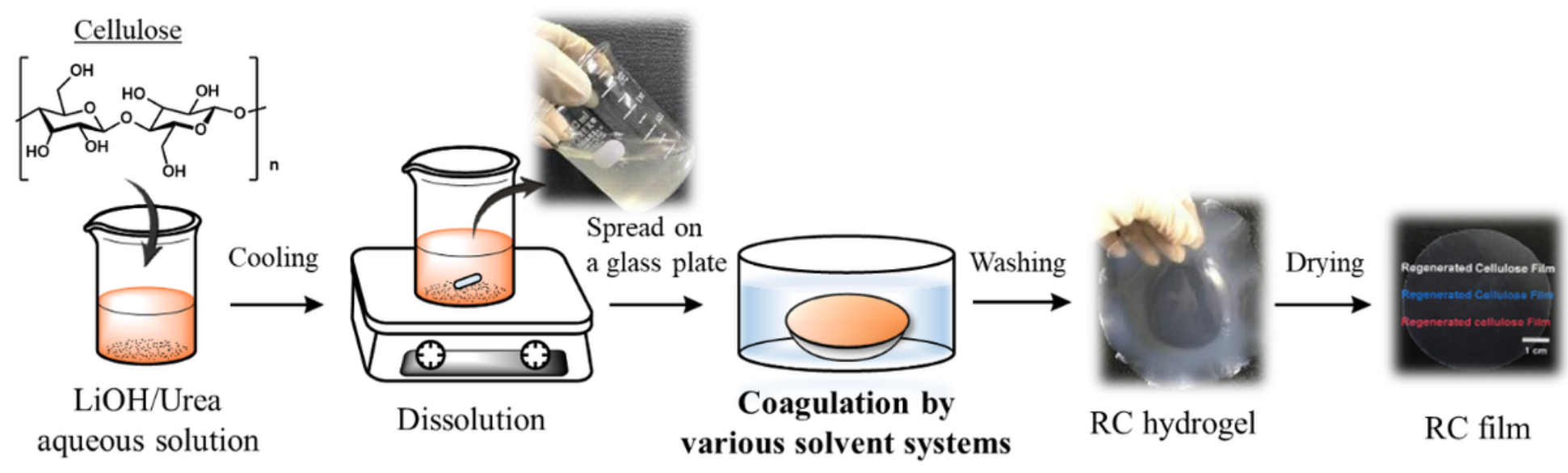

\section{Figure 1}

Schematic representation of the RC film preparation
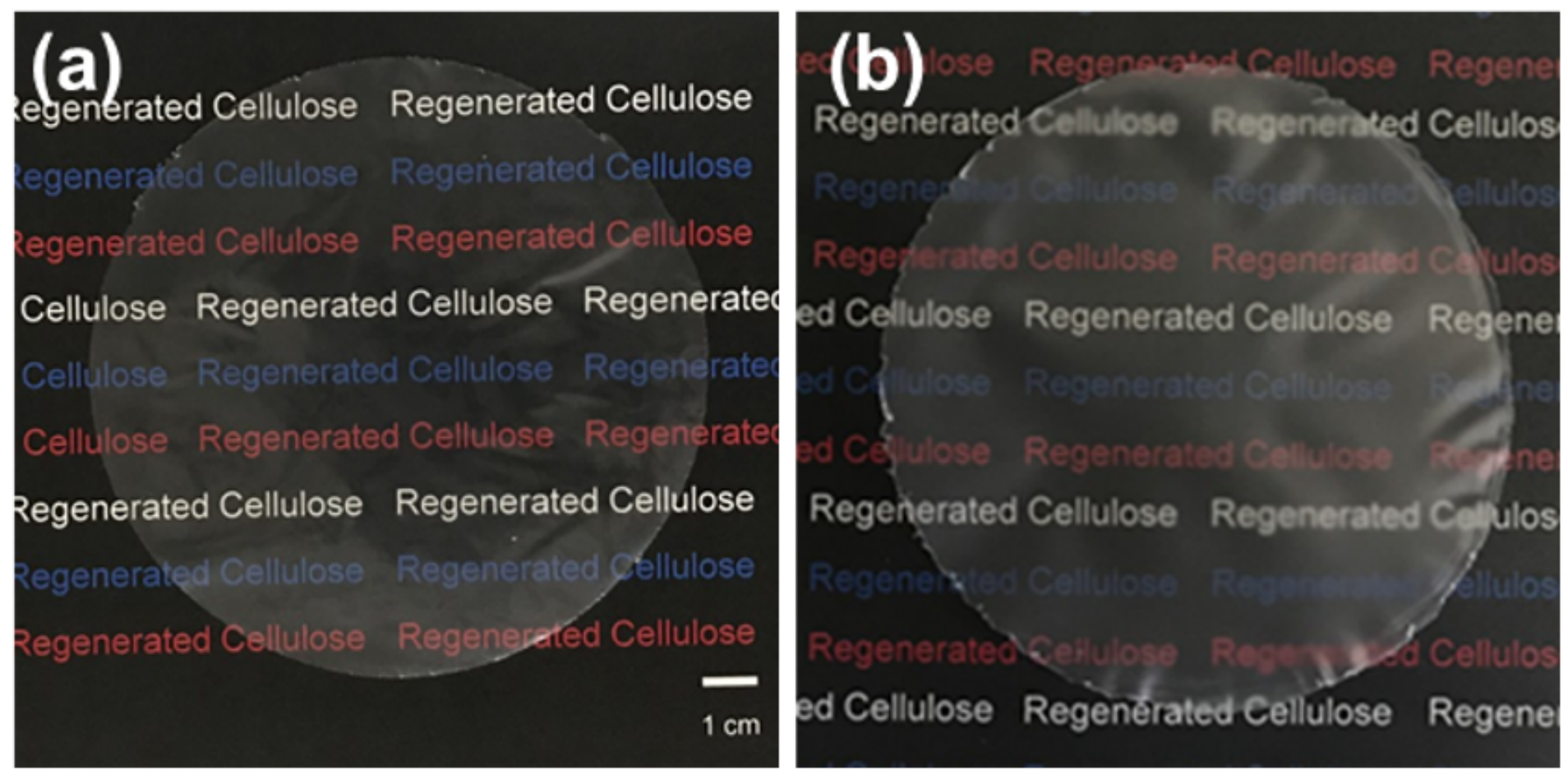
Figure 2

Images of regenerated cellulose film prepared from (a) $3 \mathrm{wt} \%$ CNF and (b) $9 \mathrm{wt} \% \mathrm{MCC}$ solution in $\mathrm{LiOH} / \mathrm{urea} / \mathrm{H} 2 \mathrm{O}$ and coagulated with methanol
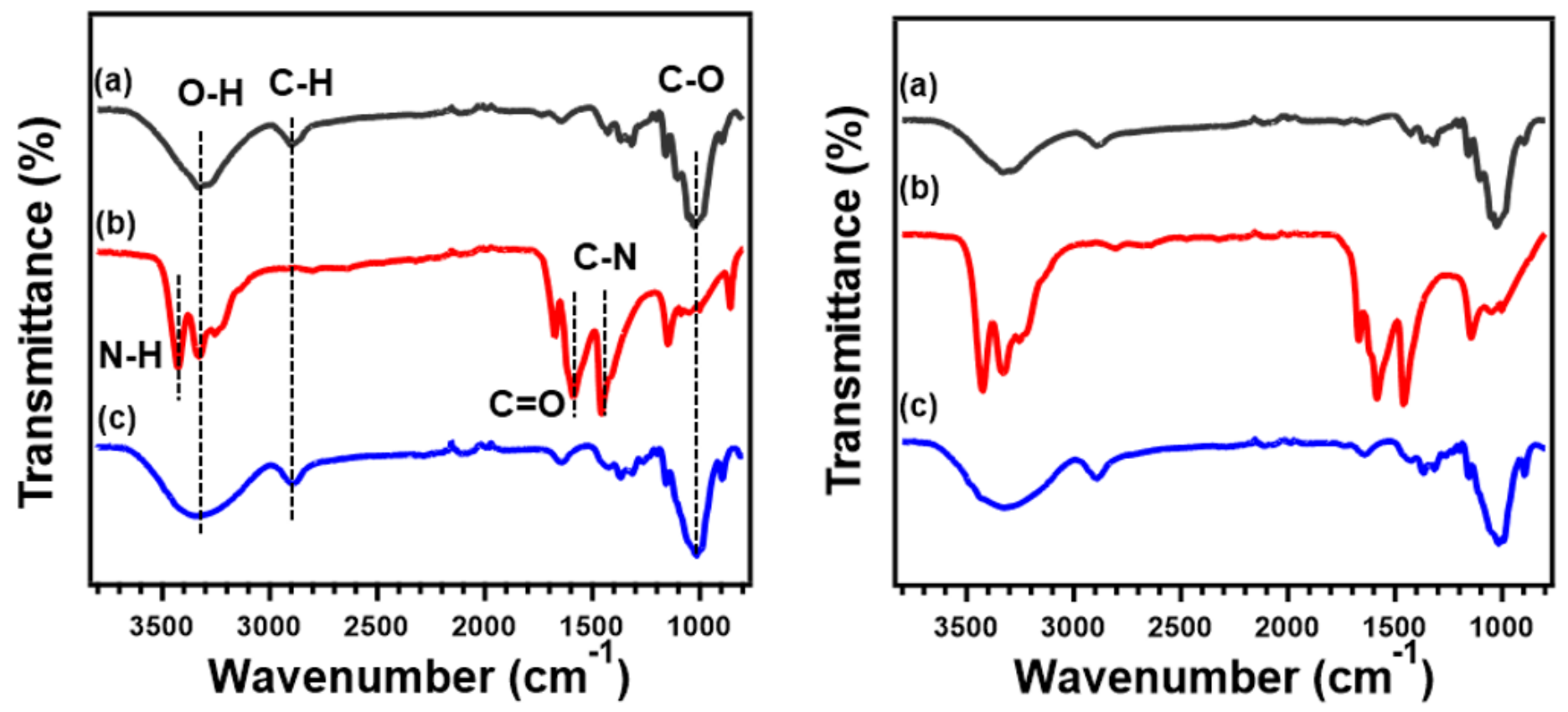

Figure 3

FT-IR spectra of (a) native cellulose, (b) dried mixture composed of cellulose, $\mathrm{LiOH}$, and urea, and (c) regenerated cellulose film regenerated with methanol based on CNF (left) and MCC (right)
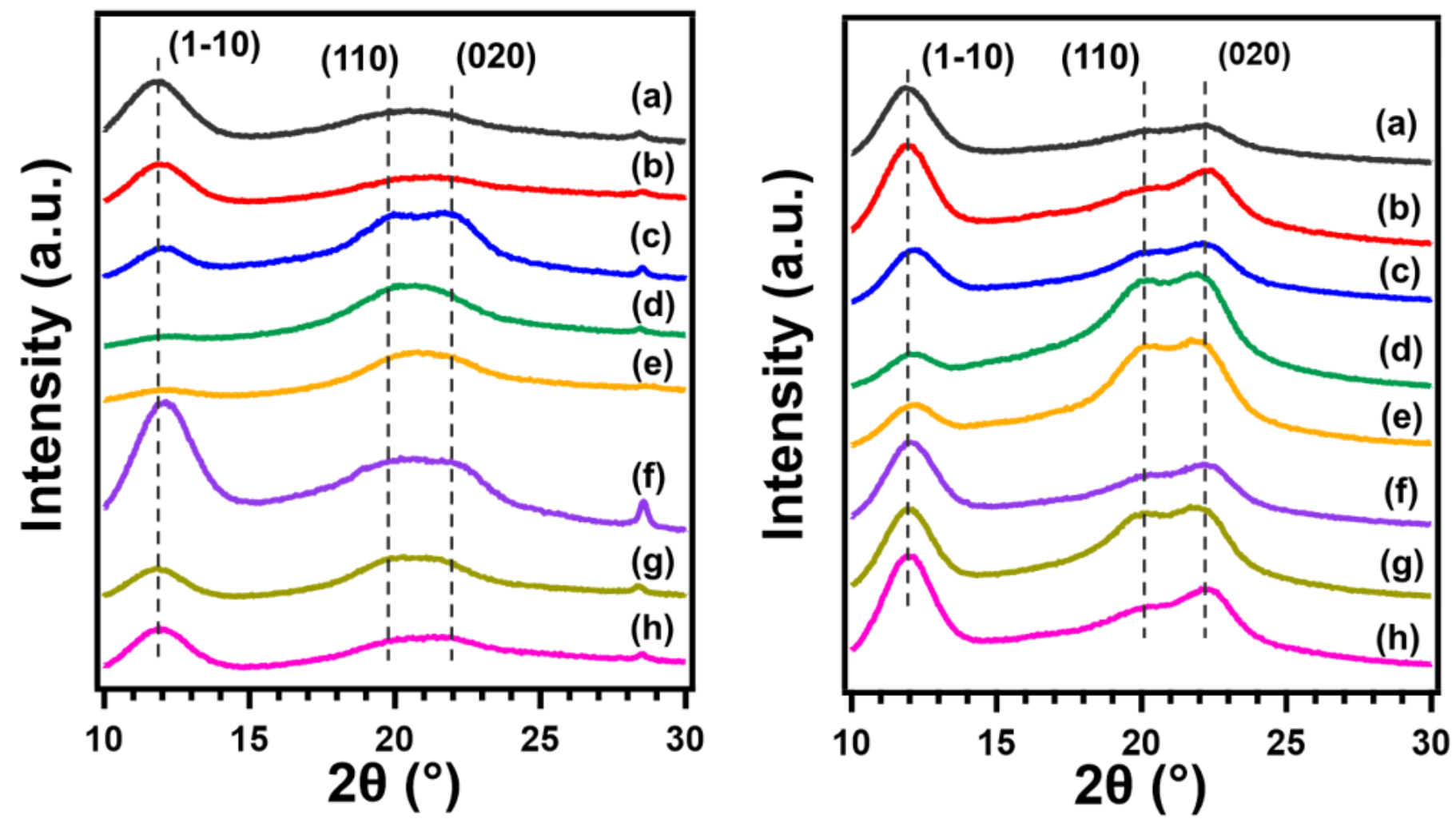
Figure 4

XRD spectra of regenerated cellulose films prepared from CNF (left) and MCC (right) through coagulation using (a) 5 wt\% H2SO4 and 5 wt\% Na2SO4 aqueous solution, (b) H2O, (c) ethylene glycol, (d) methanol, (e) ethanol, (f) 1-butanol, (g) acetone, and (h) n-hexane

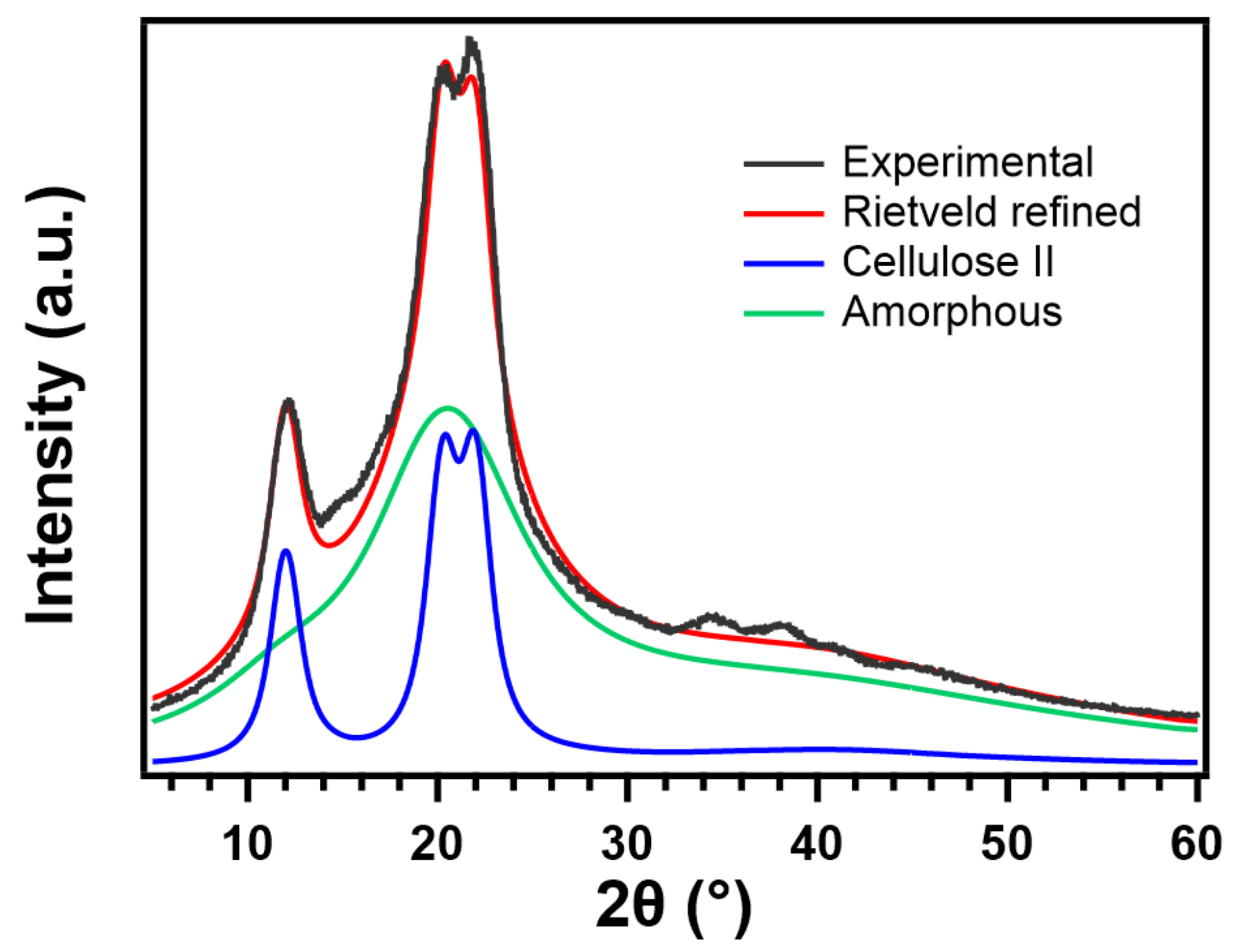

Figure 5

Measurement of the diffractogram performed on RC film prepared from MCC through coagulation using ethanol (black line), calculated total signal (red line), simulated cellulose $\nabla$ signal (blue line), and simulated amorphous phase (green line) 

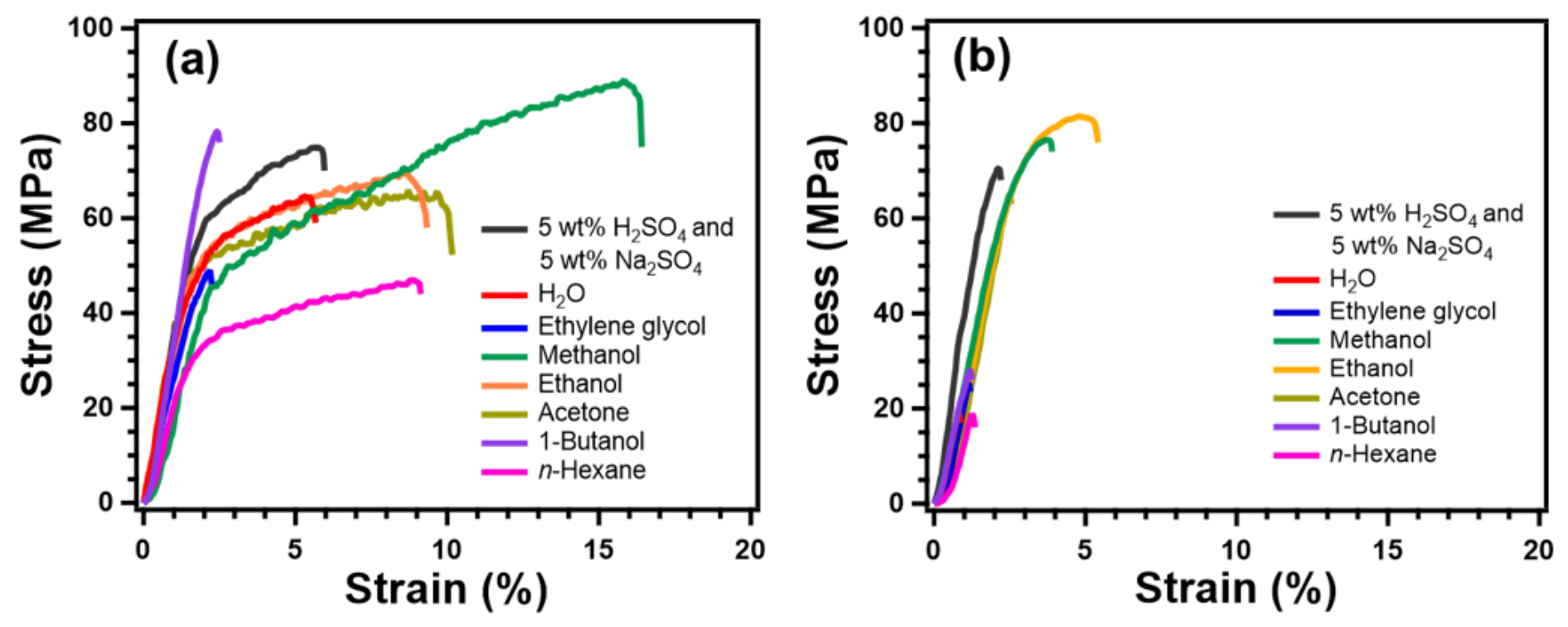

Figure 6

Stress-strain curves of regenerated cellulose films prepared from (a) CNF and (b) MCC through coagulation with various solvents 


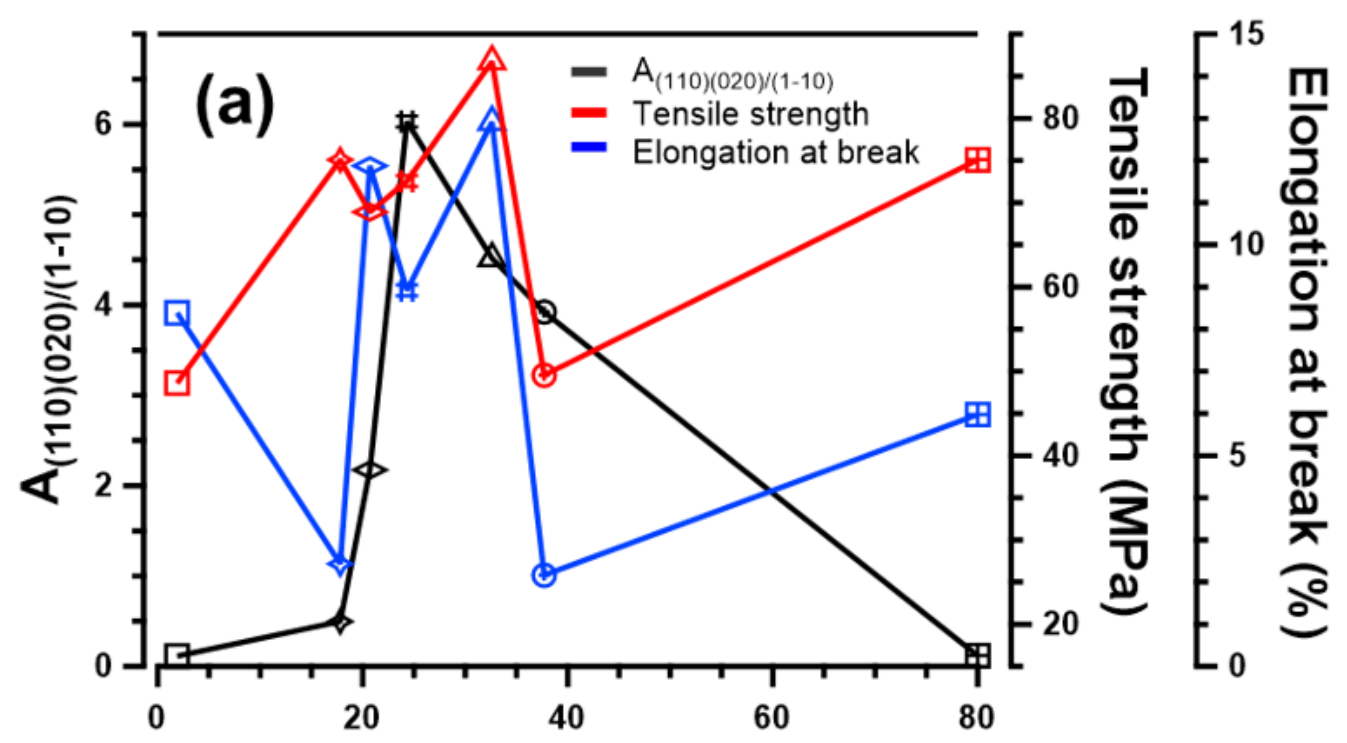

Dielectric constant

Ð $n$-Hexane $\prec$ 1-Butanol $\prec$ Acetone \#- Ethanol

$\triangle$ Methanol $\odot$ Ethylene glycol $\mathbf{Q}-\mathrm{H}_{2} \mathrm{O}$

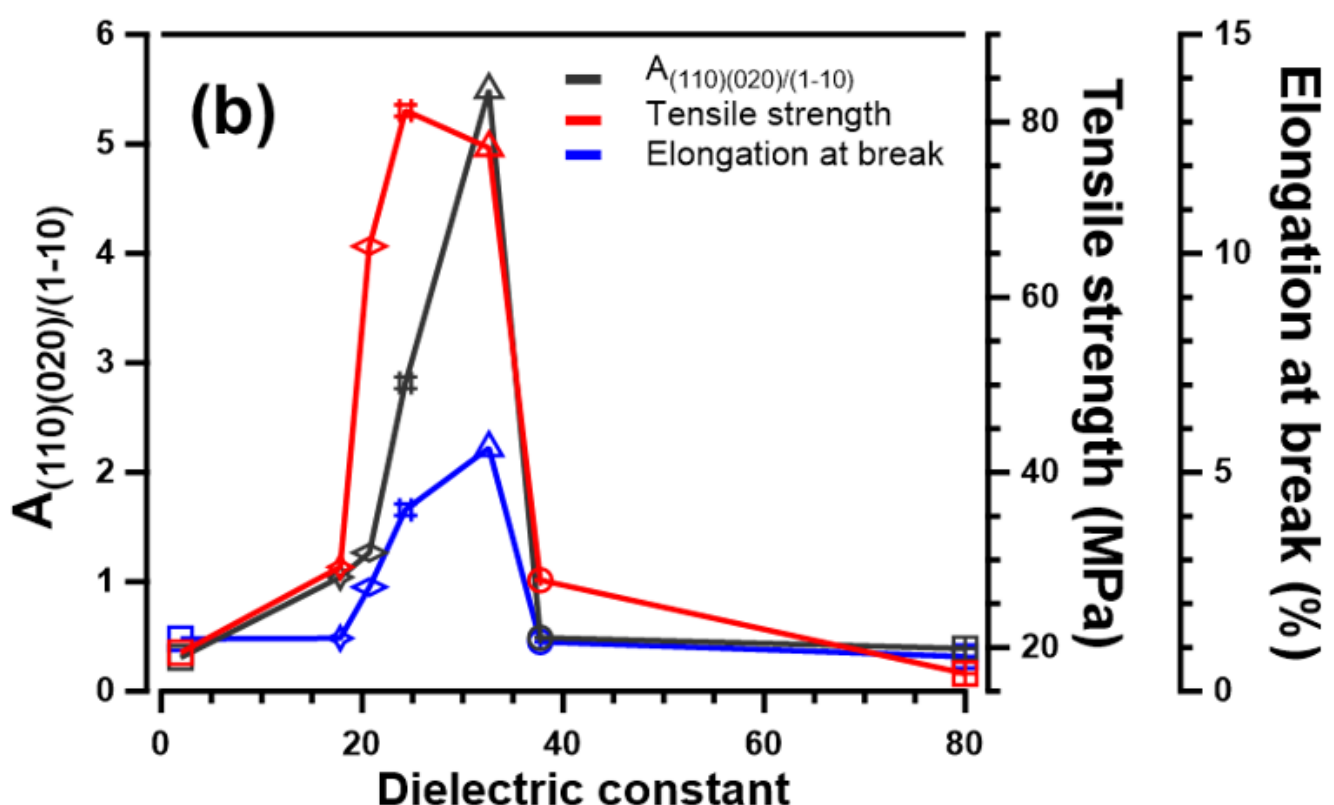

Dielectric constant

\# $n$-Hexane $\multimap$ 1-Butanol $\prec$ Acetone $\rightarrow$ Ethanol

$\triangle$ Methanol $\multimap$ Ethylene glycol $\mathbb{-}-\mathrm{H}_{2} \mathrm{O}$

Figure 7

Peak-area ratio and mechanical properties of regenerated cellulose films prepared from (a) CNF and (b) MCC as a function of coagulants dielectric constant 

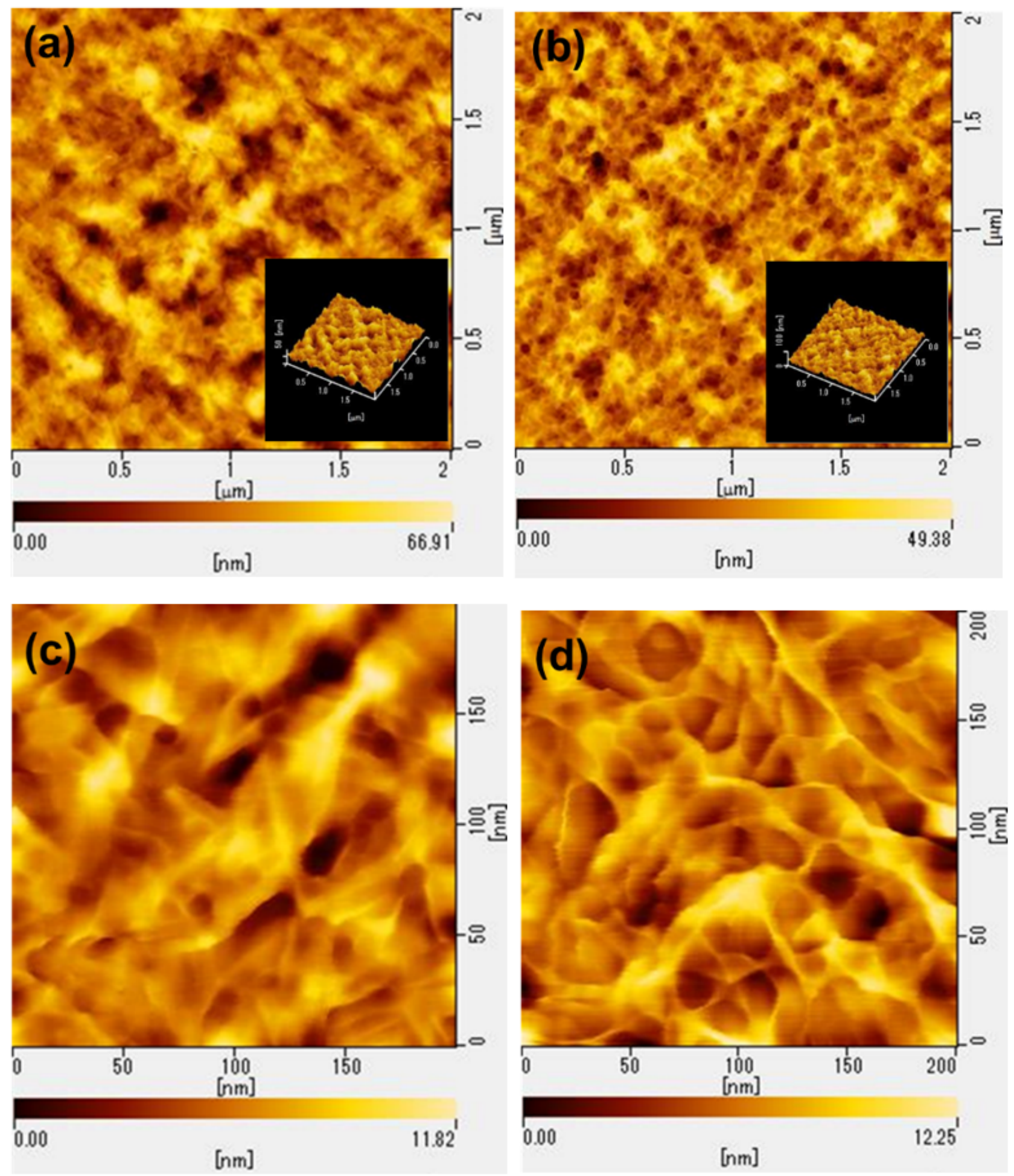

\section{Figure 8}

AFM images of regenerated cellulose films prepared from CNF through coagulation with (a and c) 5 wt\% $\mathrm{H} 2 \mathrm{SO} 4$ and $5 \mathrm{wt} \% \mathrm{Na} 2 \mathrm{SO} 4$ aqueous solution, (b and d) methanol

\section{Supplementary Files}


This is a list of supplementary files associated with this preprint. Click to download.

- SupplementaryMaterial.docx 